\title{
HUBUNGAN KEJADIAN BAYI BERAT BADAN LAHIR RENDAH DENGAN HIPERBILIRUBINEMIA
}

\author{
Dina Andesty, Rachmawati, Taliah \\ Politeknik Kesehatan Kementerian Kesehatan Bengkulu, Jurusan Kebidanan, \\ Jalan Indragiri Nomor 03 Padang Harapan Kota Bengkulu \\ bundataliah@yahoo.com
}

\begin{abstract}
According to the result of Riskesdas 2010, one of the causes of neonatal mortality in Indonesia was a blood disorder / jaundice / hyperbilirubinemia (6.6\%). Hyperbilirubinemia one of the causes of infant mortality, one of which caused low birth weight. The incidence of hyperbilirubinemia in hospitals dr.M.Yunus Bengkulu in 2013 was 8.9\%. The purpose of this study was to determine the relationship of LBW with hyperbilirubinemia in space perinatalogi dr. M. Yunus Bengkulu 2013. This study used a case-control design. The population in this study all infants born in dr. M. Yunus Bengkulu in 2013, amounting to 1,580 babies. Samples were taken for a total of 35 cases in total sampling in the ratio 1: 2 to take control using systematic random sampling technique. The study used secondary data from the register book perinatal room. Data analysis using univariate and bivariate analysis using chi-square analysis. The results showed almost half (34.3\%) experienced LBW infants and almost half (33.3\%) experienced hyperbilirubinemia. Infants with hyperbilirubinemia most $(57.1 \%)$ had low birth weight. Results of Chi-Square statistical test showed a p-value $=0.001<\alpha$ of 0.05 , meaning that there is a relationship between the incidence of LBW with hyperbilirubinemia. Obtained value $\mathrm{OR}=4.5$, which means the incidence of hyperbilirubinemia have a 4.5 times greater risk in LBW infants than non-LBW. It is recommended for health care workers, especially in the baby room can improve health care in providing midwifery care to newborns who had low birth weight and increased infant with hyperbilirubinemia handling.
\end{abstract}

Keywords: LBW, hyperbilirubinemia

\begin{abstract}
Abstrak : Menurut hasil Riskesdas 2010, salah satu penyebab kematian bayi baru lahir di Indonesia adalah kelainan darah/ikterus/hiperbilirubinemia $(6,6 \%)$. Hiperbilirubinemia salah satu faktor penyebab kematian bayi yang salah satunya disebabkan berat badan lahir rendah. Angka kejadian hiperbilirubinemia di RSUD dr.M.Yunus Bengkulu tahun 2013 adalah 8,9\%. Tujuan penelitian ini untuk mengetahui hubungan kejadian BBLR dengan hiperbilirubinemia di ruang perinatalogi RSUD dr. M. Yunus Bengkulu tahun 2013. Penelitian ini menggunakan rancangan kasus kontrol. Populasi dalam penelitian ini seluruh bayi yang lahir di RSUD dr. M. Yunus Bengkulu tahun 2013 yang berjumlah 1.580 bayi. Sampel untuk kasus sebanyak 35 diambil secara total sampling dengan perbandingan 1:2 untuk kontrol diambil menggunakan teknik systematic random sampling. Penelitian menggunakan data sekunder dari buku register di ruangan perinatal. Analisis data dengan menggunakan analisis univariat dan bivariat dengan menggunakan analisis chi-Square. Hasil penelitian menunjukkan hampir sebagian $(34,3 \%)$ bayi mengalami BBLR dan hampir sebagian $(33,3 \%)$ mengalami hiperbilirubinemia. Bayi yang mengalami hiperbilirubinemia sebagian besar $(57,1 \%)$ mengalami BBLR. Hasil uji statistik ChiSquare menunjukkan nilai $p=0,001<\alpha=0,05$, artinya ada hubungan antara kejadian BBLR dengan hiperbilirubinemia. Didapatkan nilai $\mathrm{OR}=4,5$ yang artinya kejadian hiperbilirubinemia mempunyai risiko 4,5 kali lebih besar pada bayi BBLR dibandingkan yang tidak BBLR. Disarankan bagi petugas kesehatan terutama di ruang bayi dapat meningkatkan pelayanan kesehatan dalam memberikan asuhan kebidanan kepada bayi baru lahir yang mengalami BBLR dan peningkatan penanganan bayi yang terkena hiperbilirubinemia.
\end{abstract}

Kata Kunci : BBLR, Hiperbilirubinemia 
Salah satu indikator derajat kesehatan disuatu negara dan tingkat kemajuannya dilihat dari Angka Kematian Ibu (AKI) dan Angka Kematian Bayi (AKB). Angka ini mencerminkan tingkat permasalahan kesehatan yang langsung berkaitan dengan kematian ibu dan bayi, kesehatan ibu dan bayi, dan upaya pelayanan kesehatan ibu dan bayi. Menurut World Health Organization (WHO) 2008 mengatakan bahwa AKB di Indonesia mencapai 20/1000 kelahiran hidup. Berarti setiap jam terdapat 10 bayi baru lahir meninggal, setiap hari ada 246 bayi meninggal dan setiap tahun ada 89.770 bayi baru lahir yang meninggal, adapun faktor penyebab kematian bayi diantaranya adalah sebagai berikut (prematuritas, BBLR, asfiksia, infeksi). WHO memperkirakan bahwa setiap tahun lebih dari 9 juta bayi yang meninggal pada periode perinatal dan hampir semua terjadi di negara berkembang (SDKI 2007/2008).

Menurut The UN-Inter agency Group for Child Mortality Estimates (IGME), Angka Kematian Bayi yang dimiliki Indonesia adalah 24,8 kematian per 1.000 kelahiran hidup pada 2011. Meski Angka Kematian Bayi di Indonesia terus menurun tiap tahun, namun tingkat kematian bayi di Indonesia masih tergolong tinggi jika dibandingkan dengan negara-negara anggota ASEAN, yaitu 4,2 kali lebih tinggi dari Malaysia, 1,2 kali lebih tinggi dari Filipina, dan 2,2 kali lebih tinggi dari Thailand (Profil Kesehatan Indonesia, 2012 ).

Menurut hasil Riskesdas 2010, penyebab kematian bayi baru lahir 0-6 hari di Indonesia adalah gangguan pernapasan $36,9 \%$, prematuritas $32,4 \%$, sepsis $12 \%$, hipotermi $6,8 \%$, kelainan darah/ikterus $6,6 \%$ dan lain-lain. Penyebab kematian bayi 7-28 hari adalah sepsis $20,5 \%$, kelainan kongenital $18,1 \%$, pnumonia $15,4 \%$, prematuritas dan BBLR $12,8 \%$, dan RDS 12,8\%.

Bayi Berat Badan Lahir Rendah (BBLR) adalah bayi yang lahir dengan berat badan kurang dari 2.500 gram. Bayi yang mempunyai berat badan lahir rendah sangat mempengaruhi pertumbuhan dan kecerdasan anak. Anak BBLR cenderung mempunyai pertumbuhan fisik yang terhambat dan mudah terserang penyakit. Di Bengkulu sendiri kasus BBLR tahun 2012 sebanyak 60 orang atau 1,1\% dari jumlah kelahiran hidup dan kesemuanya (100 $\%$ ) ditangani oleh tenaga kesehatan. (Dinkes Kota Bengkulu, 2012).

Menurut Yumizone (2008), komplikasi langsung yang dapat terjadi pada bayi berat badan lahir rendah, antara lain : hipotermi, hipoglikemi, gangguan cairan dan elektrolit, hiperbilirubinemia (Ikterus), syndrome gawat nafas, infeksi, perdarahan intraventikuler, apnea of prematurity dan anemia. Hiperbilirubinemia merupakan suatu kondisi bayi baru lahir dengan kadar bilirubin serum total lebih dari 10 $\mathrm{mg} \%$ pada minggu pertama yang ditandai dengan ikterus, yang dikenal dengan ikterus neonatorum patologis (Aziz Alimul, 2011).

Komplikasi yang mungkin timbul pada bayi yang menderita hiperbilirubinemia menurut Rochmah, et al (2009) meliputi kern ikterus, kerusakan otak akibat perlengketan bilirubin indirek pada otak terutama pada korpus striatum, talamus, nukleus subtalamus hipokarpus, nukleus merah didasar ventrikel IV. Menurut Retdiasty Eka Kusumawardani (2010) yang meneliti tentang Hubungan Antara Bayi Berat Lahir Rendah dengan Kejadian Hiperbilirubinemia di RSUD Prof. DR. Margono Soekardjo Purwokerto terdapat hubungan antara bayi berat lahir rendah (BBLR) dengan kejadian hiperbilirubinemia. Hal ini dapat dilihat dari nilai $p$ value sebesar 0,000 ( $p$ value $<\alpha 0,05)$.

Hiperbilirubinemia yang dialami oleh bayi dengan berat badan lahir rendah disebabkan karena belum matangnya fungsi hati bayi untuk memproses eritrosit (sel darah merah). Saat lahir hati bayi belum cukup baik untuk melakukan tugasnya. Sisa pemecahan eritrosit disebut bilirubin. Bilirubin ini yang menyebabkan ku-ning pada bayi dan apabila jumlah bilirubin semakin menumpuk ditubuhnya maka bilirubin dapat menodai kulit dan jaringan tubuh lain (Suriadi, 2004).

Hiperbilirubinemia dibagi menjadi 2 yaitu hiperbilirubinemia fisiologis dan patologis. Hiperbilirubinemia fisiologis merupakan gejala normal dan sering dialami bayi baru lahir pada 
2-4 hari setelah bayi lahir, dan akan sembuh pada hari ke 7 . Penyebabnya organ hati yang belum matang dalam memproses bilirubin. Hiperbilirubinemia Patologis adalah hiperbilirubinemia yang dikarenakan faktor patologis, misalnya akibat ketidakcocokan golongan darah, berat badan bayi kurang/ prematuritas. Yang sering mengakibatkan terjadinya hiperbilirubinemia menurut Etika (2004) adalah inkompatibilitas golongan darah ABO, Breast Milk Jaundice, inkompatibilitas golongan darah rhesus, infeksi, hematoma sefal, hematoma subdural, excessive bruising, IDM (Infant of Diabetic Mother), polisitemia/ hiperviskositas, prematuritas/BBLR, asfiksia (hipoksia, anoksia), dehidrasi - asidosis, hipoglikemia.

Berdasarkan hasil survey awal di RSUD dr. M. Yunus Bengkulu, pada tahun 2011 jumlah bayi yang lahir dan pernah dirawat sebanyak 2.174 bayi dengan kejadian BBLR sebanyak $205(9,4 \%)$ bayi dengan rincian kejadian hiperbilirubinemia sebanyak 7 (3,4\%) bayi. Pada tahun 2012 jumlah bayi yang lahir dan pernah dirawat sebanyak 2.123 bayi dengan kejadian BBLR 391 (18,4 \%) bayi dengan rincian $22(5,6 \%)$ bayi mengalami hiperbilirubinemia. Sedangkan jumlah bayi yang lahir dan pernah dirawat pada tahun 2013 yaitu 1.580 bayi dengan kejadian BBLR 392 $(24,8 \%)$ bayi dengan rincian kejadian hiperbilirubinemia sebanyak 35 (8,9\%) bayi. Berdasarkan data yang ditemukan terjadi peningkatan kejadian hiperbilirubinemia dari tahun 2011 sampai tahun 2013. Penelitian ini bertujuan untuk mengetahui hubungan bayi BBLR dengan kejadian hiperbilirubinemia di ruangan perinatalogi di RSUD dr. M. Yunus Bengkulu tahun 2013.

\section{BAHAN DAN CARA KERJA}

Jenis penelitian yang digunakan dalam penelitian ini adalah kuantitatif dengan rancangan penelitian kasus kontrol. Populasi yang digunakan dalam penelitian ini adalah semua bayi yang yang lahir di RSUD dr M. Yunus Bengkulu tahun 2013 yang berjumlah 1.580 bayi dan kejadian hiperbilirubinemia berjumlah 35 bayi. Kelompok kasus diambil secara total sampling. Kelompok control diambil dengan perbandingan $1: 2$ atau berjumlah 70 cara systematic random sampling dengan kriteria bayi yang lahir dan dirawat di ruang perinatalogi RSUD dr. M. Yunus Bengkulu periode Januari-Desember 2013. Pengumpulan data dilakukan dengan menggunakan format checklist dengan melihat register ruang perinatalogi tahun 2013. Data dianalsis secara univarita dan bivariat dengan analisis uji statistik chi kuadrat pada tingkat kepercayaan $95 \%$ dan $\alpha=0,05$.

\section{HASIL}

\section{Analisis univariat}

Hasil analisis univariat pada tabel 1 menunjukkan bahwa dari 105 sampel didapatkan hasil bahwa hampir sebagian $(34,3 \%)$ bayi mengalami BBLR dan hampir sebagian $\quad(33,3 \%) \quad$ mengalami hiperbilirubinemia.

Tabel 1 Gambaran Frekuensi Kejadian BBLR dan Hiperbilirubinemia

\begin{tabular}{lcc}
\hline Variabel & $\begin{array}{c}\text { Frekuensi } \\
(\mathbf{n = 1 0 5})\end{array}$ & $\begin{array}{c}\text { Persentase } \\
(\mathbf{\%})\end{array}$ \\
\hline Kejadian BBLR & 36 & 34,3 \\
BBLR & 69 & 65,7 \\
Tidak BBLR & & \\
Hiperbilirubinemia & & \\
Ya & 35 & 33,3 \\
Tidak & 70 & 66,7 \\
\hline
\end{tabular}

Analisis Bivariat

\begin{tabular}{|c|c|c|c|c|c|c|c|c|}
\hline Tabel 2 & & $\begin{array}{l}\text { unga } \\
\text { rbili }\end{array}$ & ubin & $\begin{array}{l}\text { BBLI } \\
\text { emia }\end{array}$ & & de & & Kejad \\
\hline \multirow{3}{*}{$\begin{array}{c}\text { Kejadian } \\
\text { BBLR }\end{array}$} & \multicolumn{4}{|c|}{ Hiperbiliru-binemia } & \multicolumn{2}{|c|}{ Total } & \multirow{3}{*}{$\begin{array}{c}\text { Nilai } \\
p\end{array}$} & \multirow{3}{*}{ OR } \\
\hline & \multicolumn{2}{|c|}{ Ya } & \multicolumn{2}{|c|}{ Tidak } & \multirow{2}{*}{ f } & \multirow{2}{*}{$\%$} & & \\
\hline & f & $\%$ & f & $\%$ & & & & \\
\hline$\overline{Y a}$ & 20 & 57,1 & 16 & 22,9 & 36 & 34,3 & & 4,500 \\
\hline Tidak & 15 & 42,9 & 54 & 77,1 & 69 & 65,7 & 0,001 & $\begin{array}{l}(1.88- \\
10,76)\end{array}$ \\
\hline
\end{tabular}

Hasil analisis pada tabel 2 menunjukkan bahwa dari 35 bayi yang mengalami hiperbilirubinemia sebagian besar $(57,1 \%)$ terjadi pada BBLR, dan hampir sebagian $(42,9 \%)$ bayi yang hiperbilirubinemia terjadi pada bayi tidak BBLR. Dari uji statistik chi-square $\left(\mathrm{x}^{2}\right)$ juga didapatkan nilai $p=0,001<(\alpha) 0,05$, berarti terdapat hubungan yang bermakna antara kejadian BBLR dengan hiperbilirubinemia, dengan $\mathrm{OR}=4,5$ yang berarti kejadian hiperbilirubinemia memiliki risiko 4,5 kali lebih 
besar terjadi pada BBLR dibandingkan dengan tidak BBLR.

\section{PEMBAHASAN}

Hasil penelitian menunjukkan bahwa hampir sebagian $(34,3 \%)$ responden yang dirawat di ruang perinatalogi RSUD dr. M. Yunus Bengkulu mengalami BBLR. Hasil penelitian ini masih cukup tinggi bila diban-dingkan dengan angka BBLR di Indonesia sebesar 10,2 $\%$.

Menurut Proverawati (2007) adapun penyebab terjadinya BBLR yaitu bersifat multifaktor: (a) Faktor ibu: ibu yang selama kehamilannya menderita penyakit seperti anemia sel berat, perdarahan antepartum, hipertensi, preeklamsi berat, eklampsi, infeksi selama kehamilan, malaria, PMS, HIV/AIDS, TORCH, usia < 20 tahun atau > 35 tahun, gameli, jarak kehamilan $<1$ tahun, riwayat BBLR, keadaan sosial ekonomi rendah dan pengawasan ANC kurang. (b) Faktor janin: infeksi janin kronik (inklusi sitogemeli, rubella bawaan), kehamilan ganda/kembar, berat plasenta berkurang/hidramnion, sindrom plasenta yang lepas dan sindrom parabiotik.

Hasil penelitian juga menunjukkan bahwa bayi yang mengalami hiperbilirubinemia sebagian besar $(57,1 \%)$ adalah BBLR. Hasil ini sesuai dengan penelitian Dwi Anita Apriliastuti (2007) di RSU Pandan Arang Boyolali, menunjukkan presentase kejadian hiperbilirubinemia akibat Inkompatibilitas golongan darah ABO sebanyak 21,74\%, asfiksia sedang sebanyak $4,35 \%$, infeksi sebanyak $30,43 \%$, dan BBLR sebanyak 43,48\%.

Hal ini sesuai dengan pendapat Yumizone (2008) yang menyatakan komplikasi langsung yang dapat terjadi pada bayi berat badan lahir rendah antara lain: hipotermi, hipoglikemi, gangguan cairan dan elektrolit, hiperbilirubinemia, syndrome gawat nafas, infeksi, perdarahan intraventikuler, apnea of prematurity dan anemia. Sedangkan masalah jangka panjang yang mungkin timbul pada bayi-bayi dengan berat badan lahir rendah (BBLR) antara lain: gangguan perkembangan, gangguan pertumbuhan, gangguan penglihatan, gangguan pendengaran, penyakit paru kronis, kenaikan angka kesakitan dan sering masuk rumah sakit dan frekuensi kelainan bawaan.

Berdasarkan hasil uji statistik menunjukkan bahwa ada hubungan yang bermakna antara bayi berat badan lahir rendah dan hiperbilirubinemia (nilai $p=0,001<0,05$ ) dengan nilai Odds Ratio (OR) sebesar 4,5 yang artinya kejadian hiperbilirubinemia memiliki risiko 4,5 kali lebih besar terjadi pada BBLR dibandingkan dengan tidak BBLR. Hasil penelitian ini sesuai dengan penelitian Kusumawardani (2010) di RSUD Prof. DR. Margono Soekardjo Purwokerto tahun 2010 yang mengatakan terdapat hubungan antara bayi berat badan lahir rendah (BBLR) dengan kejadian hiperbilirubinemia $(p=0,000<(\alpha)$ $0,05)$.

Hasil ini juga sesuai dengan pengamatan dan penelitian di RSCM Jakarta yang menunjukkan bahwa suatu hiperbilirubinemia bila bayi mengalami ikterus yang disertai dengan keadaan berat badan lahir kurang dari 2500 gram (Winkjosastro, 2007). Hiperbilirubinemia yang dialami oleh bayi dengan berat badan lahir rendah disebabkan karena belum matangnya fungsi hati bayi untuk memproses eritrosit (sel darah merah). Pada bayi, usia sel darah merah kira-kira 90 hari kemudian eritrosit harus diproses oleh hati bayi sebagai hasil pemecahannya. Saat lahir hati bayi belum cukup baik untuk melakukan tugasnya. Sisa pemecahan eritrosit disebut bilirubin, bilirubin ini yang menyebabkan kuning pada bayi dan apabila jumlah bilirubin semakin menumpuk ditubuhnya maka, bilirubin dapat menodai kulit dan jaringan tubuh lain (Suriadi, 2004).

Hasil penelitian menemukan bahwa bayi yang terkena hiperbilirubinemia hampir sebagian $(42,9 \%)$ tidak mengalami berat badan lahir rendah. Hal ini sejalan dengan penelitian Septiani. N, (2012) menunjukkan bahwa faktor-faktor yang berpengaruh terhadap kejadian hiperbilirubinemia pada neonatus yaitu $12,3 \%$ usia kehamilan < 37 minggu, 12,5\% usia kehamilan 37-42 minggu, 12,1\% usia kehamilan > 42 minggu, 9,4\% berat badan lahir < 2500 gram, 15,7 berat badan 2500-4000 gram, $17,5 \%$ dengan golongan jenis dengan persa- 
linan spontan, $12,3 \%$ seksio sesarea, $12,4 \%$ vakum, dan forceps $12,1 \%$.

Menurut penelitian yang pernah dilakukan sebelumnya juga oleh Hardian (2008) bahwa memang kejadian hiperbili-rubinemia pada neonatus bisa disebabkan oleh persalinan dengan tindakan salah satunya dengan ekstrasi vakum karena bisa terjadi cidera dan infeksi ke bayi yang lahir dengan vakum. Selain bayi berat badan lahir rendah penyebab terjadinya hiperbilirubinemia adalah inkompatibilitas golongan darah $\mathrm{ABO}$, inkompatibilitas golongan darah rhesus, infeksi, hematoma sefal, Infant of Diabetic Mother (IDM), asfiksia, dan hipoglikemia (Etika, 2004).

\section{KESIMPULAN}

Berdasarkan hasil penelitian dan analisis data mengenai hubungan kejadian BBLR

\section{DAFTAR RUJUKAN}

Davies, Lorna \& Sharon Mcdonald. 2011. Pemeriksaan Kesehatan Bayi. Jakarta: EGC

Depkes RI. 2007. Profil Kesehatan Indonesia. Jakarta: 2010. Riset Kesehatan Dasar. Jakarta: 2012. Profil Kesehatan Indonesia. Jakarta:

Dewi, Vivian Nanny Lia. 2012. Asuhan Neonatus Bayi dan Anak Balita. Jakarta: Salemba Medika

Dinkes Kota Bengkulu. 2012. Profil Dinas Kesehatan Provinsi Bengkulu. Bengkulu:

Etika, R., Harianto, A., \& Indarso, F. 2010. Hiperbilirubinemia pada neonatus. Terdapat pada http://retdiastydanish.blogspot.com/2011/12/artikelhubungan-antara-bayi-berat.html . Diakses tanggal 10 Februari 2014

Hidayat, A. Aziz Alimul. 2011. Pengantar Ilmu Kesehatan Anak untuk Pendidikan Kebidanan. Jakarta: Penerbit Salemba Medika

2012. Pengantar Ilmu Keperawatan Anak I. Jakarta: Penerbit Salemba Medika

Indiarti, MT. 2007. Panduan Lengkap Kehamilan, Persalinan \& Perawatan bayi. Yogyakarta: Diglossia Media dengan hiperbilirubinemia di ruang perinatalogi RSUD dr. M. Yunus Bengkulu tahun 2013 diperoleh kesimpulan bahwa hampir sebagian responden dengan BBLR, dan terdapat kejadian hiperbilirubinemia memiliki risiko 4,5 kali lebih besar terjadi pada BBLR dibandingkan dengan tidak BBLR di ruang perinatalogi RSUD dr. M. Yunus Bengkulu tahun 2013.

Diharapan petugas kesehatan di RSUD dr. M. Yunus Bengkulu hendaknya lebih meningkatkan pelayanan kesehatan dalam memberikan asuhan kepada bayi baru lahir yang mengalami berat badan lahir rendah supaya dapat perhatian lebih terutama dalam asuhan nutrisi dan perawatan serta pemberian konseling terhadap orang tua bayi yang tidak BBLR agar tidak terkena hiperbilirubinemia agar bayinya diberi cukup ASI dan rajin dijemur pada pagi hari.

Manuaba, I.B.G. 2006. Ilmu Kebidanan, penyakit Kandungan dan keluarga Berencana. Jakarta: EGC

Notoadmodjo, Soekidjo. 2012. Metodelogi Penelitian Kesehatan. Jakarta: Rineka Cipta

Proverawati, Atikah dan Cahyo Ismawati. 2010. Berat Badan Lahir Rendah (BBLR). Yogyakarta: Nuha Medika

Rochma, dkk. 2009. Asuhan Neonatus, Bayi, \& Balita. Jakarta: Penerbit Buku Kedokteran EGC.

Suriadi, 2004. Hubungan BBLR dengan Hiperbilirubinemia. Diakses pada Januari 2014 dari http//www.google.com

Syaifuddin, Bari Abdul. 2005. Buku Ajar Nasional Pelayanan Kesehatan Maternal dan Neonatal. Jakarta: Yayasan Bina Pustaka

Wiknjosastro, Hanifa. 2007. Ilmu Kebidanan. Jakarta: Yayasan Bina Sarwono Prawirohardjo

Wong, Donna L. 2004. Pedoman Klinis Keperawatan Pediatrik. Jakarta: EGC

Yumizone, 2008. Berat Badan Lahir Rendah. (http//www.google.com), diakses pada Januari 2014. 